\title{
Nesticus kosodensis Yaginuma, 1972 bona species. Molecular and morphological separation from N. latiscapus Yaginuma, 1972 with notes on cave scaffold-web spiders subspecies in Japan (Araneae, Nesticidae)
}

\author{
Yuya Suzuki', Francesco Ballarin²
}

I Graduate School of Life and Environmental Science, University of Tsukuba, 1-1-1, Tennodai, Tsukuba-shi, Ibaraki, 305-8572, Japan 2 Systematic Zoology Laboratory, Department of Biological Sciences, Tokyo Metropolitan University, 1-1 Minami-Osawa, Hachioji-shi, 192-0397, Tokyo, Japan

Corresponding author: Francesco Ballarin (ballarin.francesco@gmail.com)

Academic editor: M. Pavlek | Received 5 May 2020 | Accepted 8 June 2020 | Published 5 August 2020

http://zoobank.org/AD56D17C-0722-4420-AD41-210089ECC283

Citation: Suzuki Y, Ballarin F (2020) Nesticus kosodensis Yaginuma, 1972 bona species. Molecular and morphological separation from $N$. latiscapus Yaginuma, 1972 with notes on cave scaffold-web spiders subspecies in Japan (Araneae, Nesticidae). Subterranean Biology 35: 79-96. https://doi.org/10.3897/subtbiol.35.53933

\begin{abstract}
The troglophilic spider subspecies Nesticus latiscapus kosodensis Yaginuma, 1972 is compared with its nominal species $N$. latiscapus Yaginuma, 1972 using an integrated taxonomic approach. Both morphological and molecular analysis suggest the two taxa are distinct, rejecting the status of subspecies. In the light of these results, $N$. kosodensis stat. nov. is elevated to species level and both species are redescribed. We expect that future revisions of Japanese Nesticidae will find that many currently designated subspecies are in fact distinct species. Taxonomic revision of long-established and unrevised subspecies may help to improve the conservation efforts aiming to protect the Japanese endemic cave fauna.
\end{abstract}

\section{Keywords}

Asia, troglophilic spiders, species elevation, stat. nov., subterranean environment

Copyright Yuya Suzuki, Francesco Ballarin. This is an open access article distributed under the terms of the Creative Commons Attribution License (CC BY 4.0), which permits unrestricted use, distribution, and reproduction in any medium, provided the original author and source are credited. 


\section{Introduction}

Defining the boundaries among species is a key factor in modern systematics (Wiens 2007). Due to its arbitrariness across different taxonomic groups, the correct separation between geographic forms in polytypic species (= subspecies) from closely related but distinct congeners may be tricky. Although the use of subspecies is accepted by the International Code of Zoological Nomenclature (ICZN 2012), their use in spider taxonomy has decreased substantially during the last century; they are often limited to old descriptions from the first half of the $20^{\text {th }}$ century or earlier (Kraus 2000; Nentwig et al. 2019). Revisiting established spider subspecies using a more modern approach is necessary to confirm their taxonomic status as local variants of the same species or, alternatively, to include them in a different taxonomic rank (e.g. a separate species).

Nesticidae Simon,1894 is a family of spiders (16 genera and 278 species, World Spider Catalog 2020) with a worldwide distribution. Most nesticids inhabit caves or subterranean environments, but some are found in other places characterized by relatively uniform conditions of temperature and humidity along the year (e.g. deep cracks in rocks, humid and shadowed valleys, tropical forest litter, etc.). In Japan the nesticid fauna appears to be particularly diverse, with five genera and 59 recorded species and subspecies, the wide majority of which (54 taxa) are included in the genera Nesticus Thorell, 1869 and Cyclocarcina Komatsu, 1942 (Tanikawa 2020). Most of the Japanese nesticid species show high levels of endemism being often restricted to one of few caves and consequently can be considered good candidates for species conservation. Nevertheless, among the Japanese Nesticus and Cyclocarcina species 10 of them $(-20 \%$ of the total) are currently considered subspecies, all of which were established in the 1970s by Prof. Takeo Yaginuma: Cyclocarcina floronoides komatsui Yaginuma 1979; C. floronoides notoi Yaginuma 1979; C. floronoides tatoro Yaginuma 1979; Nesticus akiyoshiensis ofuku Yaginuma 1977; N. latiscapus kosodensis Yaginuma 1972; N. longiscapus awa Yaginuma 1978; N. longiscapus draco Yaginuma 1978; N. longiscapus kiuchii Yaginuma 1978; N. tosa iwaya Yaginuma 1976; and N. tosa niyodo Yaginuma 1976. The validity of these interspecific names has not yet been tested using more recent taxonomic techniques.

During field trips in central Japan (Yamanashi and Tokyo Prefectures), we collected several fresh specimens of the subspecies Nesticus latiscapus kosodensis Yaginuma, 1972 and its nominal species N. latiscapus Yaginuma, 1972. These spiders are found in caves and similar environments within a relatively restricted area in central Japan. Due to their presumed morphological similarities and close geographic distributions, $N$. latiscapus kosodensis has long been considered a variant of $N$. latiscapus. The aim of this study is to compare the morphology and genetic distances of these two taxonomic units, and test the concept of subspecies among Japanese cave spiders.

\section{Materials and methods}

Collecting sites were centred in Yamanashi and Tokyo Prefectures, central Japan. Spider samples were predominantly collected from caves, but some were found under rocks. 
Specimens were preserved in 95\% ethanol for molecular and morphological analysis. Specimen morphology was examined using a Nikon SMZ1270 stereomicroscope (for $N$. latiscapus) or a Nikon AZ100M stereomicroscope (for $N$. kosodensis stat. nov.), and photographed with a Canon EOS Kiss x8i digital camera attachment. Photos were combined using the image stacking software Helicon Focus 6.7.1. and further processed with Adobe Photoshop CC 2015. Epigynes were dissected using a sharp scalpel, and cleared by boiling them in a $20 \% \mathrm{KOH}$ solution for several minutes until clear. Leg measurements are reported in the text as total length (femur, patella, tibia, metatarsus, tarsus). All measurements are in millimeters. The following abbreviations are used in text or figures: $\mathrm{Be}=$ bulge of embolus; $\mathrm{Co}=$ copulatory opening; Dp1-3 = dorsal processes of paracymbium; $\mathrm{Di}=$ distal process of paracymbium; $\mathrm{E}=$ embolus; $\mathrm{Id}+\mathrm{Fd}=$ insemination and fertilization ducts; $\mathrm{Ma}=$ median apophysis; $\mathrm{P}=$ paracymbium; $\mathrm{Pc1}-3$ = processes of conductor complex; $\mathrm{S}=$ spermatheca; $\mathrm{Sc}=$ scapus; $\mathrm{St}=$ subtegulum; $\mathrm{T}=$ tegulum; $\mathrm{Ta}=$ tegular apophysis; $\mathrm{Vp}=$ vulval pocket; $\mathrm{Vpp}=$ ventral process of paracymbium. Specimens used in this study are stored in the following collections: $\mathrm{FBPC}=\mathrm{F}$. Ballarin personal collection; YSPC $=$ Y. Suzuki personal collection; NSMT = National Museum of Nature and Science, Tokyo, Japan; TSPC: T. Suguro personal collection.

\section{Molecular analysis}

Fresh specimens were identified at species level and subsequently stored at $-20^{\circ}$ at the Systematic Zoology Laboratory, Department of Biological Sciences, Tokyo Metropolitan University, Japan (TMU). DNA extraction and Polymerase Chain Reaction amplification (PCR) of the samples were performed in the same institute. Total genomic DNA was extracted using a Qiagen DNeasy Blood \& Tissue Kit following the standard protocol suggested by the manufacturer. A fragment of the mitochondrial gene Cytochrome c oxidase subunit I (COI) was selectively amplified using the primers LCO1490 (forward) GGTCAACAAATCATCATAAAGATATTGG (Folmer et al. 1994) and C1-N-2776 (reverse) GGATAATCAGAATATCGTCGAGG (Hedin \& Maddison 2001). PCR amplifications were performed using a SimpliAmp Thermal Cycler (Thermo Fisher Scientific, U.S.) with a final volume of $11 \mu \mathrm{l}$ under the following protocol: $94^{\circ}\left(2^{\prime}\right)$; [98 $\left.\left(10^{\prime \prime}\right), 45^{\circ}\left(30^{\prime \prime}\right), 68^{\circ}\left(10^{\prime \prime}\right)\right]$ x5; [94 $\left(10^{\prime \prime}\right), 50^{\circ}\left(30^{\prime \prime}\right)$, $\left.68^{\circ}\left(45^{\prime \prime}\right)\right]$ x40; $68^{\circ}\left(7^{\prime}\right)$. Purified PCR products were submitted and sequenced by Eurofins Genomics Company, Tokyo branch. Final sequences were aligned using the online version of MAFFT v.7.450 (Katoh et al. 2019) under the G-INS-i. algorithm and translated to proteins using MEGA X v.10.0.5 (Kumar et al. 2018) to check for potential errors. A maximum likelihood (ML) analysis, under a GTRGAMMA nucleotide substitution model as suggested by JModelTest 2 v.2.1.7 (Darriba et al. 2012), was performed using the online version of RAxML v.8.2.12 (Stamatakis 2014) on CIPRES Science Gateway v.3.3 (Miller et al. 2010, available at: https://www.phylo.org/). One thousand replicates of rapid bootstrap were performed twice under a GTRGAMMA model. Uncorrected pairwise-distance genetic divergences between the species were retrieved using MEGA X under a bootstrap method, with 1000 replications. The list of 
species used in the analysis, and related GenBank accession numbers of the sequences, are reported in Table 2.

In order to evaluate the genetic distance between the taxa discussed in this study and other close related congeners from the same geographical area, a total of 13 Nesticus specimens belonging to four species were included in the analysis: $N$. kosodensis stat. nov. (4 specimens), N. latiscapus (7 specimens), N. shinkaii Yaginuma, 1979 and $N$. gondai Yaginuma, 1979 (1 specimen each). The latter two species were preferentially selected on the base of their geographic distribution and results of our preliminary studies on the phylogeny of the genus Nesticus. The phylogenetic tree was rooted using the species Cyclocarcina floronoides tatoro (Yaginuma 1979), since our preliminary results also suggest a close phylogenetic relationship between Cyclocarcina and the Japanese components of the genus Nesticus. The final alignment was 663 nucleotides long.

\section{Results}

\section{Phylogenetic analysis}

Maximum likelihood analysis (Fig. 9) confirms a close phylogenetic relationship between $N$. latiscapus and $N$. kosodensis stat. nov., with these taxa belonging to two sister clades. However, the two clades have relatively long branches, indicating a rather high difference in the number of substitutions per site. Such genetic distance is even higher than the distance among other valid species of the same genus included in the analysis, thus rejecting the hypothesis of $N$. latiscapus and $N$. kosodensis stat. nov. being conspecifics. The pairwise distance analysis (Table 1) further supports this clear separation, reporting a genetic distance of $\sim 10 \%$ from each other, and between them and other congeners.

Table I. Uncorrected genetic p-distance between Nesticus latiscapus, $N$. kosodensis stat. nov., and the other outgroup species based on the COI partial sequence discussed in the text.

\begin{tabular}{|c|c|c|c|c|c|c|c|c|c|c|c|c|c|c|}
\hline & & 1 & 2 & 3 & 4 & 5 & 6 & 7 & 8 & 9 & 10 & 11 & 12 & 13 \\
\hline 1 & Cy185 Nesticus latiscapus & & & & & & & & & & & & & \\
\hline 2 & Cy184 Nesticus latiscapus & 0.002 & & & & & & & & & & & & \\
\hline 3 & Cy401 Nesticus latiscapus & 0.000 & 0.002 & & & & & & & & & & & \\
\hline 4 & Cy405 Nesticus latiscapus & 0.000 & 0.002 & 0.000 & & & & & & & & & & \\
\hline 5 & Cy408 Nesticus latiscapus & 0.002 & 0.000 & 0.002 & 0.002 & & & & & & & & & \\
\hline 6 & Cy077 Nesticus latiscapus & 0.002 & 0.000 & 0.002 & 0.002 & 0.000 & & & & & & & & \\
\hline 7 & Cy044 Nesticus latiscapus & 0.000 & 0.002 & 0.000 & 0.000 & 0.002 & 0.002 & & & & & & & \\
\hline 8 & Cy190 Nesticus kosodensis & 0.103 & 0.102 & 0.103 & 0.103 & 0.102 & 0.102 & 0.103 & & & & & & \\
\hline 9 & Cy041 Nesticus kosodensis & 0.106 & 0.105 & 0.106 & 0.106 & 0.105 & 0.105 & 0.106 & 0.027 & & & & & \\
\hline 10 & Cy042 Nesticus kosodensis & 0.106 & 0.105 & 0.106 & 0.106 & 0.105 & 0.105 & 0.106 & 0.027 & 0.000 & & & & \\
\hline 11 & Cy406 Nesticus kosodensis & 0.102 & 0.100 & 0.102 & 0.102 & 0.100 & 0.100 & 0.102 & 0.002 & 0.026 & 0.026 & & & \\
\hline 12 & Cy191 Nesticus gondai & 0.092 & 0.091 & 0.092 & 0.092 & 0.091 & 0.091 & 0.092 & 0.097 & 0.095 & 0.095 & 0.095 & & \\
\hline 13 & Cy189 Nesticus shinkaii & 0.095 & 0.094 & 0.095 & 0.095 & 0.094 & 0.094 & 0.095 & 0.106 & 0.103 & 0.103 & 0.105 & 0.068 & \\
\hline 14 & $\begin{array}{l}\text { Cy1 } 183 \text { Cyclocarcina } \\
\text { floronoides tatoro }\end{array}$ & 0.085 & 0.083 & 0.085 & 0.085 & 0.083 & 0.083 & 0.085 & 0.100 & 0.100 & 0.100 & 0.098 & 0.041 & 0.073 \\
\hline
\end{tabular}


Table 2. Localities and related GenBank accession numbers of the specimens used in the molecular analysis. New sequences are indicated by an asterisk.

\begin{tabular}{|c|c|c|c|}
\hline Code & Species & COI & Locality \\
\hline Cy184 & Nesticus latiscapus & MT524181* & $\begin{array}{c}\text { Japan, Yamanashi Prefecture, Minamitsuru-gun, Fujikawaguchiko-machi, } \\
\text { Saiko Bat Cave (西湖蝙蝠穴) }\end{array}$ \\
\hline Cy185 & Nesticus latiscapus & MT524180* & $\begin{array}{c}\text { Japan, Yamanashi Prefecture, Minamitsuru-gun, Fujikawaguchiko-machi, } \\
\text { Ryugu Doketsu Cave (龍宮洞穴) }\end{array}$ \\
\hline Cy401 & Nesticus latiscapus & MT524182* & $\begin{array}{c}\text { Japan, Yamanashi Prefecture, Minamitsuru-gun, Fujikawaguchiko-machi, } \\
\text { Narusawa Ice Cave (鳴沢水穴) }\end{array}$ \\
\hline Cy405 & Nesticus latiscapus & MT524183* & $\begin{array}{c}\text { Japan, Yamanashi Prefecture, Minamitsuru-gun, Fujikawaguchiko-machi, } \\
\text { Fugaku Wind Cave (富岳風穴) }\end{array}$ \\
\hline Cy408 & Nesticus latiscapus & MT524184* & $\begin{array}{c}\text { Japan, Yamanashi Prefecture, Minamitsuru-gun, Fujikawaguchiko-machi, } \\
\text { surroundings of Saiko Bat Cave (西湖蝙蝠穴) }\end{array}$ \\
\hline Cy077 & Nesticus latiscapus & MT524185* & $\begin{array}{c}\text { Japan, Yamanashi Prefecture, Minamitsuru-gun, Fujikawaguchiko-machi, } \\
\text { Narusawa area }\end{array}$ \\
\hline Сy044 & Nesticus latiscapus & MT524186* & $\begin{array}{c}\text { Japan, Yamanashi Prefecture, Minamitsuru-gun, Narusawa-mura, } \\
\text { unnamed lava tunnel }\end{array}$ \\
\hline Cy190 & Nesticus kosodensis & MT524187* & $\begin{array}{c}\text { Japan, Tokyo Prefecture, Nishitama-gun, Okutama-machi, Nippara, } \\
\text { Nippara Cave (日原鍾乳洞) }\end{array}$ \\
\hline Сy406 & Nesticus kosodensis & MT524190* & $\begin{array}{c}\text { Japan, Tokyo Prefecture, NishitamA-gun, Okutama, Nippara, } \\
\text { surroundings of Nippara Cave (日原鍾乳洞) }\end{array}$ \\
\hline Cy041 & Nesticus kosodensis & MT524188* & Japan, Yamanashi Prefecture, Kitatsuru-gun, Kosuge-mura, under stones \\
\hline Cy042 & Nesticus kosodensis & MT524189* & Japan, Yamanashi Prefecture, Kitatsuru-gun, Kosuge-mura, under stones \\
\hline Cy189 & Nesticus shinkaii & MT524192* & Japan, Tokyo Prefecture, Akiruno-shi, Yozawa. Otake Cave (大岳鍾乳洞) \\
\hline Cy191 & Nesticus gondai & MT524191* & $\begin{array}{l}\text { Japan, Gunma Prefecture, Annaka-shi, Sakamoto, Matsuida-machi, } \\
\text { Kirizumi-gawa river valley, near Kirizumi onsen }\end{array}$ \\
\hline Cy183 & $\begin{array}{l}\text { Cyclocarcina } \\
\text { floronoides tatoro }\end{array}$ & MG201049 & $\begin{array}{c}\text { Japan, Gunma Prefecture, Tano-gun, Kanna-machi, Kagahara, Mt. } \\
\text { Tatoro, Tatoro Cave (立処山鍾乳洞) }\end{array}$ \\
\hline
\end{tabular}

\section{Taxonomy}

\section{Family Nesticidae Simon, 1894 \\ Genus Nesticus Thorell, 1869}

\section{Nesticus kosodensis Yaginuma, 1972, stat. nov.}

Figures 1a-c, 2-4, 8a, b

Nesticus latiscapus kosodensis Yaginuma, 1972: 295, f. 20-23 (ð゚ㅇ).

N. latiscapus kosodensis Yaginuma, 1977: 315, pl. 2, f. 4 (う).

N. latiscapus kosodensis Yaginuma, 1979: 265, pl. 7, f. 2, 4 (ぷ+).*

Material examined. Holotype. JAPAN - Honshu Island • $\hat{\sigma}$; Yamanshi Prefecture, Kitatsuru-gun, Tabayama-mura, Kosode Limestone Cave (小袖鍾乳洞); [35.7938N, 138.9722E]; 3 Feb. 1969, Akama H. leg.; NSMT-Ar 70 (as N. latiscapus kosodensis).

Paratype. JAPAN - Honshu Island $\bullet 1+$; same data as the holoype; NSMT-Ar 71 (as N. latiscapus kosodensis).

\footnotetext{
* For the complete list of references see the World Spider Catalog 2020.
} 


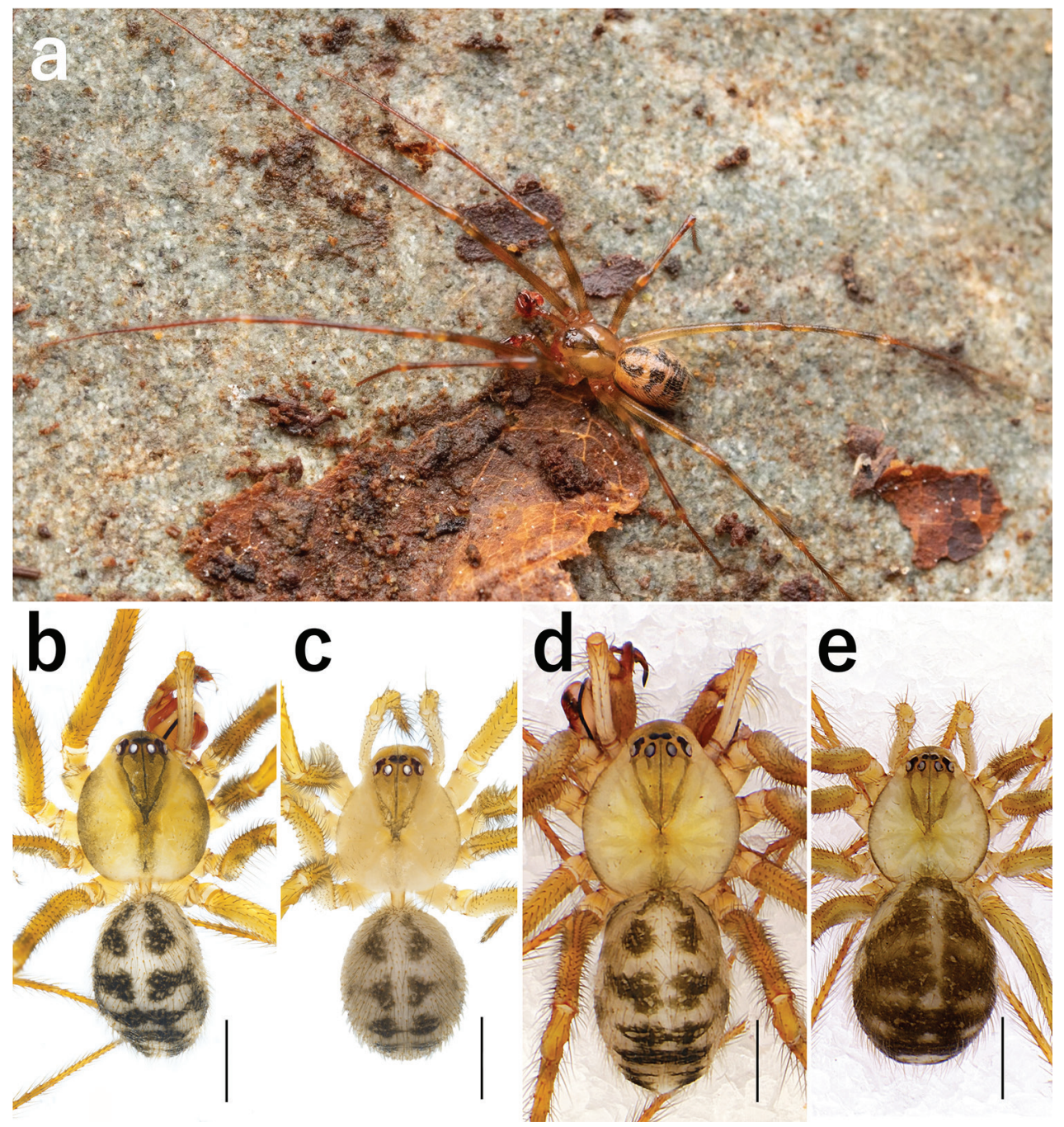

Figure I. Habitus of Nesticus kosodensis stat. nov. and N. latiscapus. a, b $N$. kosodensis stat. nov. adult male c ditto, adult female $\mathbf{d} N$. latiscapus, adult male e ditto, adult female. Scale bars: $1 \mathrm{~mm}$.

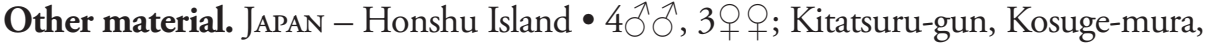
Hashitate, Odaki (雄滝); 35.74476N, 138.88462E; 10 Nov. 2019, Suzuki Y. leg.; under stones; YSPC, FBPC • 4우; Tokyo Prefecture, Nishitama-gun, Okutama-machi, Nippara, Nippara Limestone Cave (日原鍾乳洞); 35.8524N, 139.0407E; Ballarin F. leg.; FBPC.

Diagnosis. Species closely related to Nesticus latiscapus, but both sexes can be distinguished by the morphology of the genitalia. Male $N$. kosodensis stat. nov. can be separated from male $N$. latiscapus by the following combination of characters: Dp2 and Dp3 close to each other (separated from each other in $N$. latiscapus, see Fig. $3 \mathrm{~b}$ vs. $6 \mathrm{~b}$ ); Di narrower, lacking a serrated edge (Di wider and bearing a serrated edge 

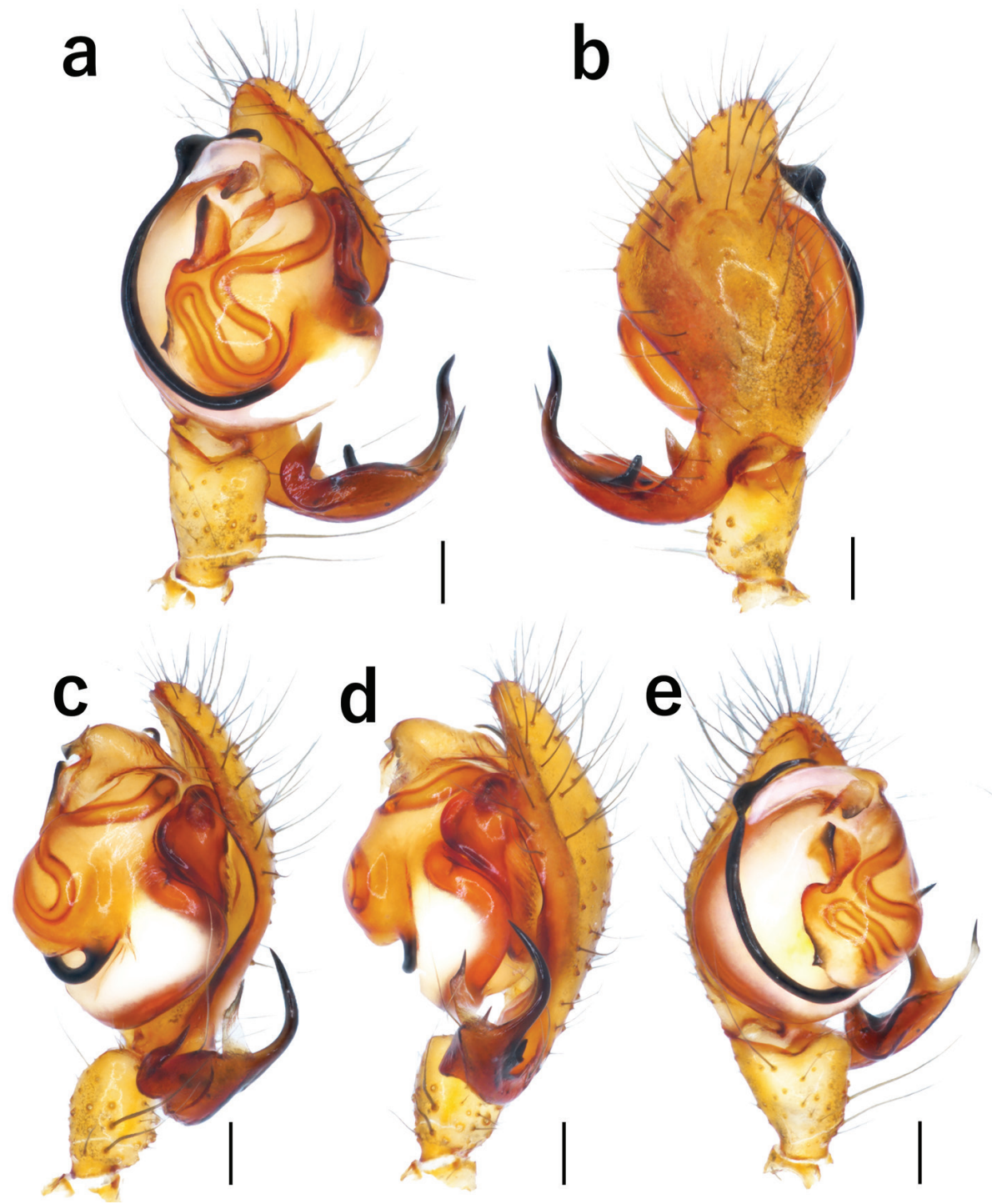

Figure 2. Male palp of $N$. kosodensis stat. nov. from Odaki area: a ventral view b dorsal view c ventroretrolateral view $\mathbf{d}$ retrolateral view e ventro-prolateral view. Scale bars: $0.2 \mathrm{~mm}$.

in $N$. latiscapus, see Fig. 3d vs. 6d); Ma weakly protruding (Ma strongly protruding in $N$. latiscapus, see Fig. 3e vs. 6e); Be present (Be absent in $N$. latiscapus, see Fig. 3a, b vs. 6a, b); Ta weakly developed but present (lacking in $N$. latiscapus, see Fig. 3a, e vs. 6a, e). Females $N$. kosodensis stat. nov. are distinguished from females $N$. latiscapus by the different shape of scapus, narrower towards the tip and with convergent edges in $N$. kosodensis stat. nov., almost of the same width or slightly wider towards the tip, with slightly divergent edges and lobate corners in $N$. latiscapus (Fig. 4 vs. Fig. 7). The 

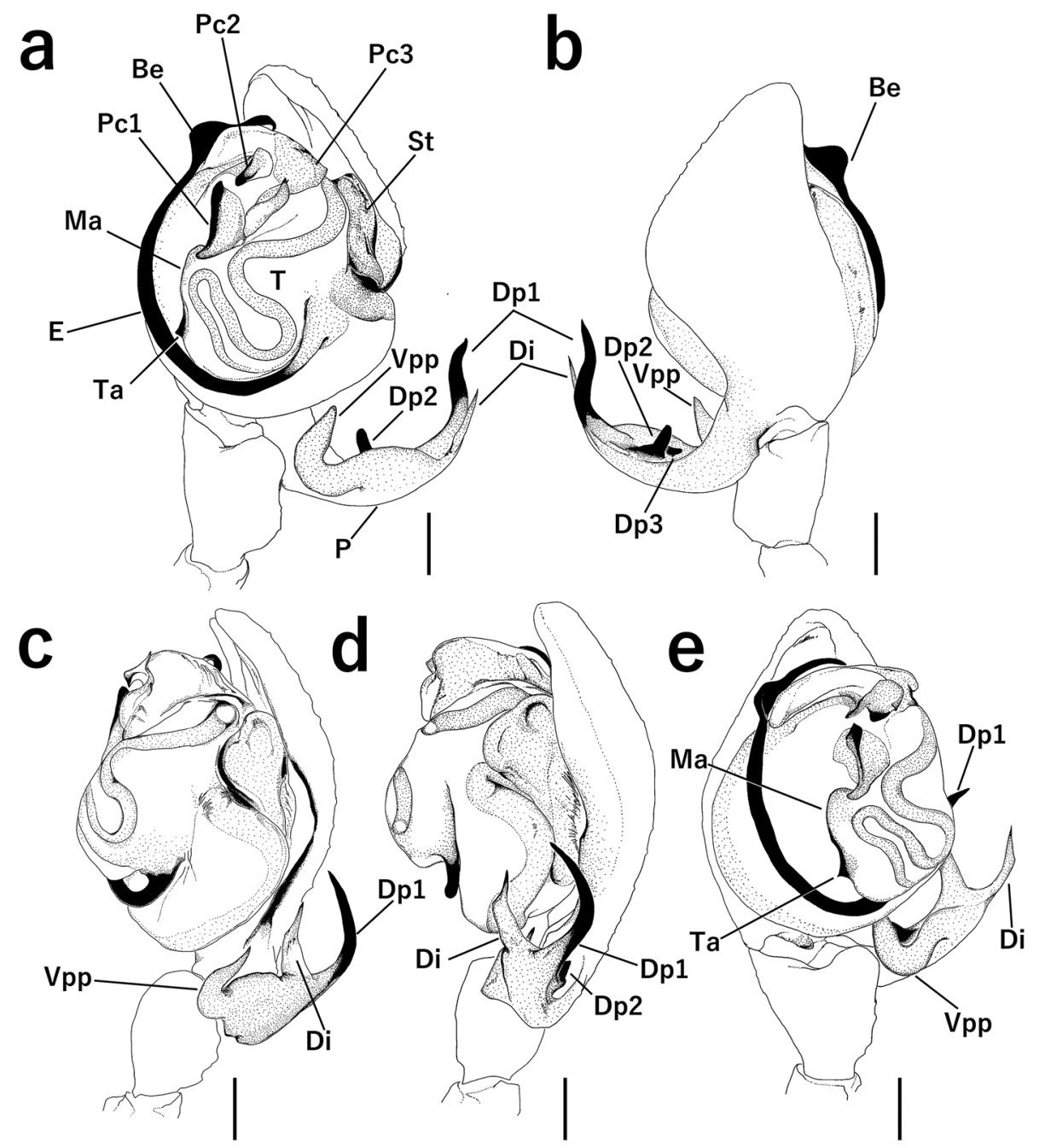

Figure 3. Male palp of $N$. kosodensis stat. nov. (illustrated): a ventral view $\mathbf{b}$ dorsal view $\mathbf{c}$ ventro-retrolateral view $\mathbf{d}$ retrolateral view e ventro-prolateral view. Scale bars: $0.2 \mathrm{~mm}$.

shape of copulatory openings is also different between the two species: the edge of the opening is curved and slanted compared to the edge of the scapus in $N$. kosodensis stat. nov., but straight and parallel to the edge of the scapus in N. latiscapus (Fig. 4 vs. Fig. 7).

Redescription. Male. Total length: 4.00-4.29, carapace: 1.77-2.01 long, 1.041.75 wide (based on three males).

Habitus as in Fig. 1a, b. Carapace light yellowish brown, midline and lateral edges darker. Chelicera, labium and sternum light yellowish-brown without any markings. Legs yellowish-brown with dark bands. Leg measurements as follows (based on one male): I 15.60 (4.34, 0.83, 4.62, 4.21, 1.61), II 12.10 (3.48, 0.77, 3.32, 3.18, 1.34), 

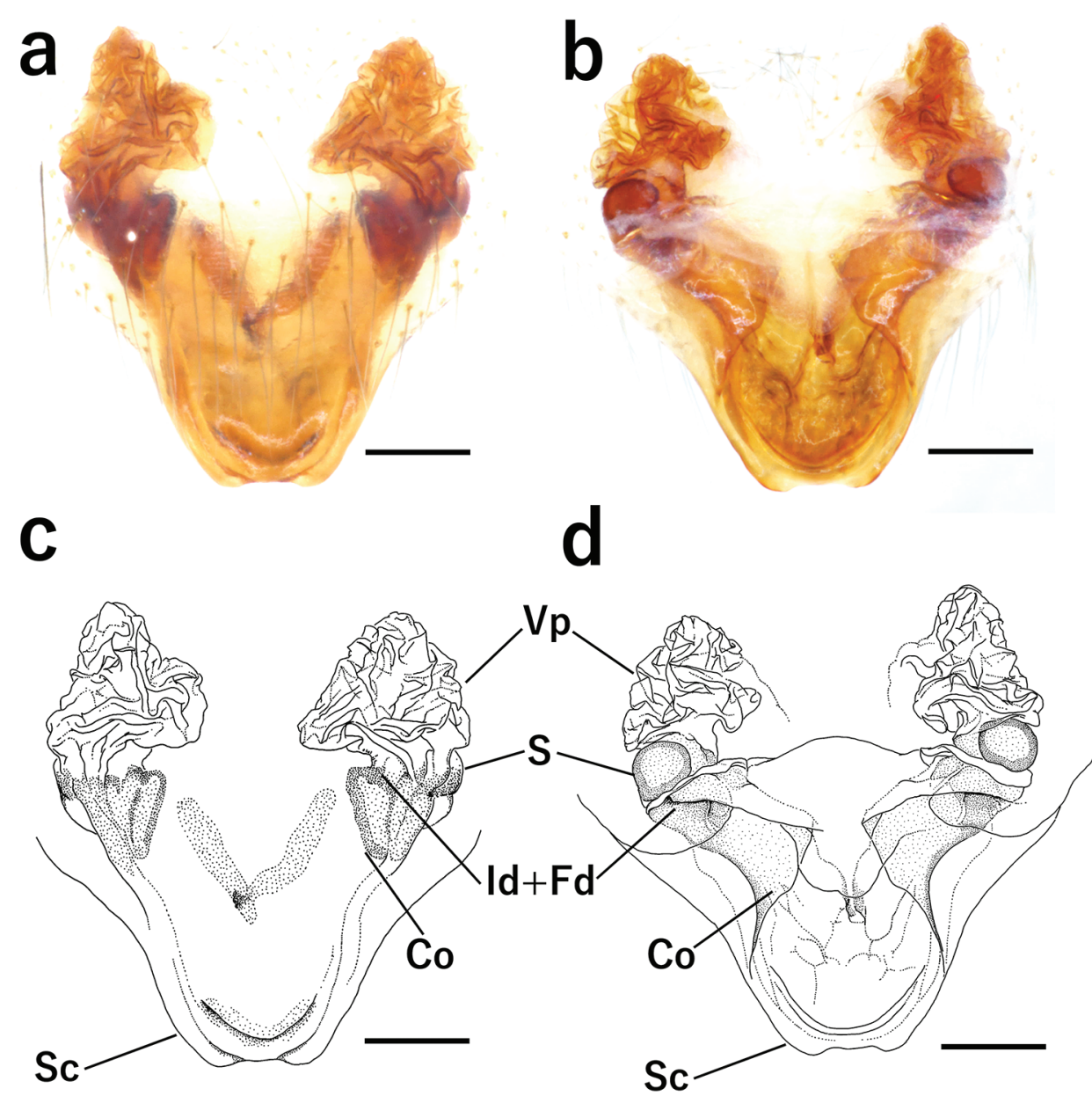

Figure 4. Female genitalia of $N$. kosodensis stat. nov. from Odaki area. a, c Epigyne, ventral view b, d vulva, dorsal view. Scale bars: $0.2 \mathrm{~mm}$.

III $8.55(2.60,0.58,2.25,2.14,0.98)$, IV 11.70 (3.68, 0.70, 3.09, 2.97, 1.25). Dorsum of abdomen whitish-yellow with narrowly spaced pairs of black markings posteriorly.

Palp as in Figs 2, 3, 8a. Paracymbium with five processes: ventral process recurved, dorsal process 1 sharp and weakly curved when the palp is observed ventrally and laterally, dorsal process 2 short and straight, dorsal process 3 very small and close to the basal part of dorsal process 2, hidden behind ventral process when the palp is observed ventrally. All dorsal processes strongly sclerotized. Distal process of paracymbium sharp with a smooth edge. Embolus with a well-developed bulge, median apophysis weakly protruded, tegular apophysis small and triangular.

Female. Total length: 3.73-3.90, carapace: 1.61-1.73 long, 1.46-1.47 wide (based on two females). 
Habitus as in Fig. 1c. Color and markings as in the male. Legs measurements as following (based on one female): I 12.80 (3.76, 0.71, 3.53, 3.30, 1.48), II 9.57 (2.77, $0.69,2.55,2.40,1.16)$, III 6.34 (1.96, 0.58, 1.62, 1.38, 0.80), IV 9.51 (3.03, 0.67, $2.48,2.27,1.06)$.

Epigyne and vulva as in Figs 4, 8b. Scapus prolonged posteriorly, narrower towards the tip, with slightly convergent edges and bearing a U-shaped groove. Edge of copulatory openings rounded and slanted compared to the edge of the scapus. Insemination and fertilization ducts reaching spermathecae with a short and convoluted trait. Spermathecae oval. Vulval pockets strongly wrinkled, located above spermathecae.

Distribution. Endemic to central Honshu, Japan (Yamanashi and Tokyo Prefectures). See Fig. 10.

\section{Nesticus latiscapus Yaginuma, 1972}

Figures 1d, e, 5-7, 8c, d

Nesticus latiscapus Yaginuma, 1972: 291, f. 16-19 (ํํㅇ).

N. latiscapus Yaginuma, 1979: 264, pl. 7, f. 1, 3 (ð゚).**

Material examined. Holotype. JAPAN - Honshu Island • $\widehat{\jmath}$; Yamanashi Prefecture, Minamitsuru-gun (former Kamikuishiki-mura), Aokigahara, Shoji-o-ana cave, Nichido cave (精進御穴日洞); [35.4709N, 138.6385E]; 2 Nov. 1969, Ueno S. \& Kato K. leg.; NSMT-Ar 61.

Paratype. JAPAN - Honshu Island • 19; same data as the holotype; NSMT-Ar 62.

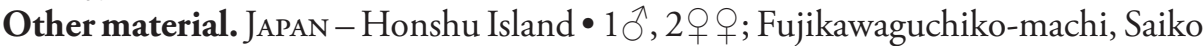
Bat Cave (西湖蝙蝠穴); 35.4942N, 138.6714E; 09 Oct. 2014; Ballarin F. leg.; FBPC - 1ð̄, 2 우; same locality, Ryugu Doketsu Cave (龍宮洞穴); 35.4855N, 138.6683E; 09 Oct. 2014; Ballarin F. leg.; FBPC • 19; same locality, Narusawa Ice Cave (鳴沢水 穴); 35.4745N, 138.6665E; 10 Oct. 2014; Ballarin F. leg.; FBPC • 1; same locality, Fugaku Wind Cave (富岳風穴); 35.4775N, 138.6571E; 10 Oct. 2014・3ふふふ, 2우, Narusawa-mura, unnamed lava tunnel; 35.4749N, 138.6831E; 01 Apr. 2019; Ballarin F. leg.; FBPC • 1ð̊, 1; Narusawa area, 18 Aug. 2017, Suguro T. leg; TSPC.

Diagnosis. See diagnosis of $N$. kosodensis stat. nov.

Redescription. Male. Total length: 3.86-4.30 carapace: 1.87-2.02 long, 1.581.81 wide (based on three males).

Habitus as in Fig. 1d. Coloration and shape as in N. kosodensis stat. nov., some specimens with light-colored midline and lateral edges of carapace. Leg measurements as following (based on one male): I 16.16 (4.31, 0.83, 4.77, 4.57. 1.68), II 12.21 $(3.38,0.81,3.37,3.27,1.38)$, III 9.17 (3.01, 0.65, 2.16, 2.36, 0.99), IV 12.23 (3.84, $0.70,3.18,3.26,1.25)$.

Palp as in Figs 5, 6, 8c. Paracymbium with five processes: ventral process recurved, narrower at the basal part, dorsal process 1 sharp, weakly curved when observed lat-

\footnotetext{
** For the complete list of references see the World Spider Catalog 2020.
} 


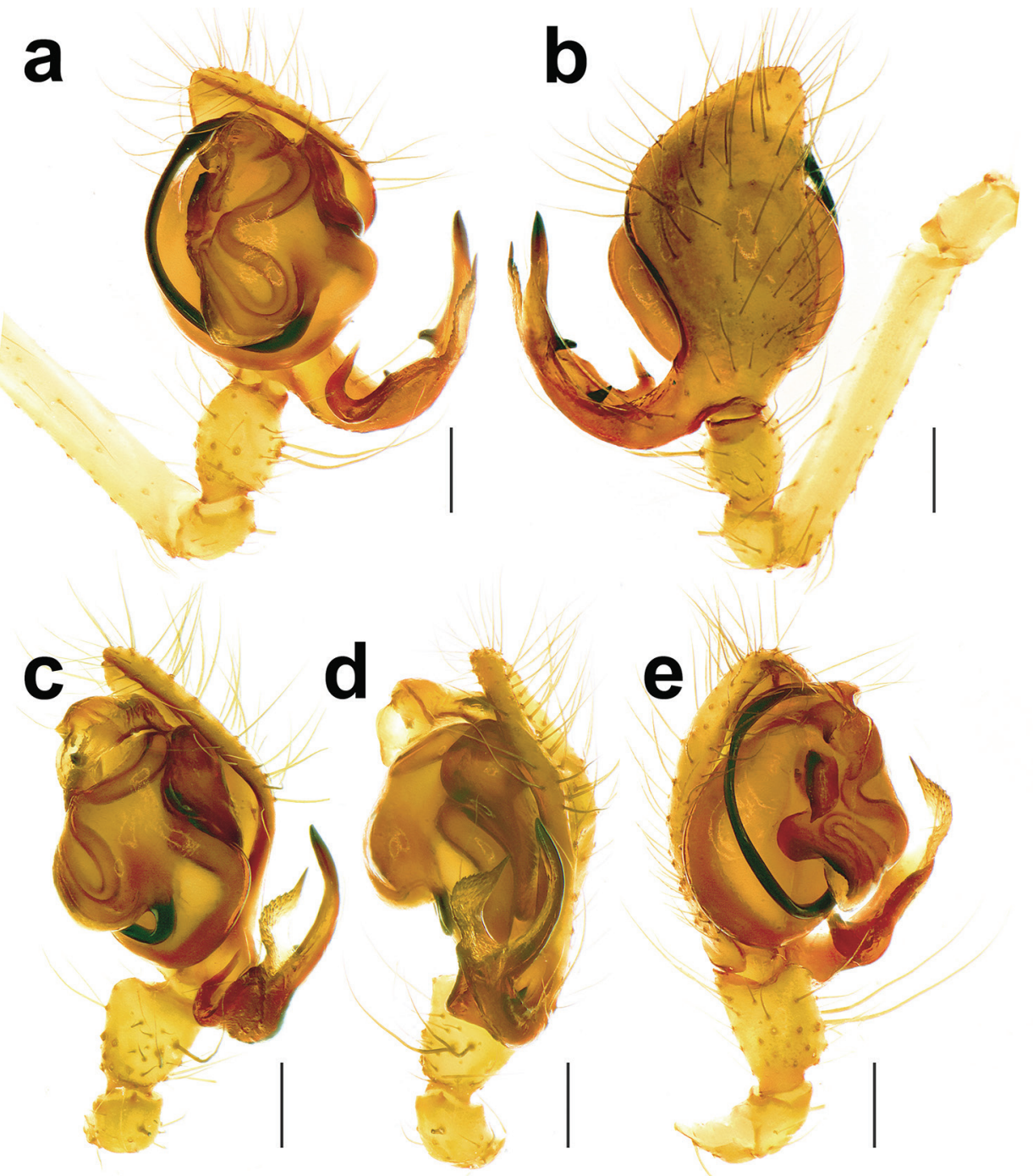

Figure 5. Male palp of $N$. latiscapus from Saiko Bat Cave. a Ventral view b dorsal view c ventro-retrolateral view $\mathbf{d}$ retrolateral view $\mathbf{e}$ ventro-prolateral view. Scale bars: $0.2 \mathrm{~mm}$.

erally and ventrally, dorsal process 2 short and straight, dorsal process 3 small, distal process wing-shaped, with a serrated edge. Bulge of embolus absent, median apophysis lobate, strongly protruded prolaterally, tegular apophysis absent.

Female. Total length: 3.91-4.43, carapace: $1.68-1.72$ long, $1.47-1.59$ wide (based on three females).

Habitus as in Fig. 1e. Coloration and shape as in N. kosodensis stat. nov., some specimens with abdomen dorsal markings large and fused, giving a general darker coloration. Legs measurements as following (based on one female): I 15.67 (4.44, 0.94, 


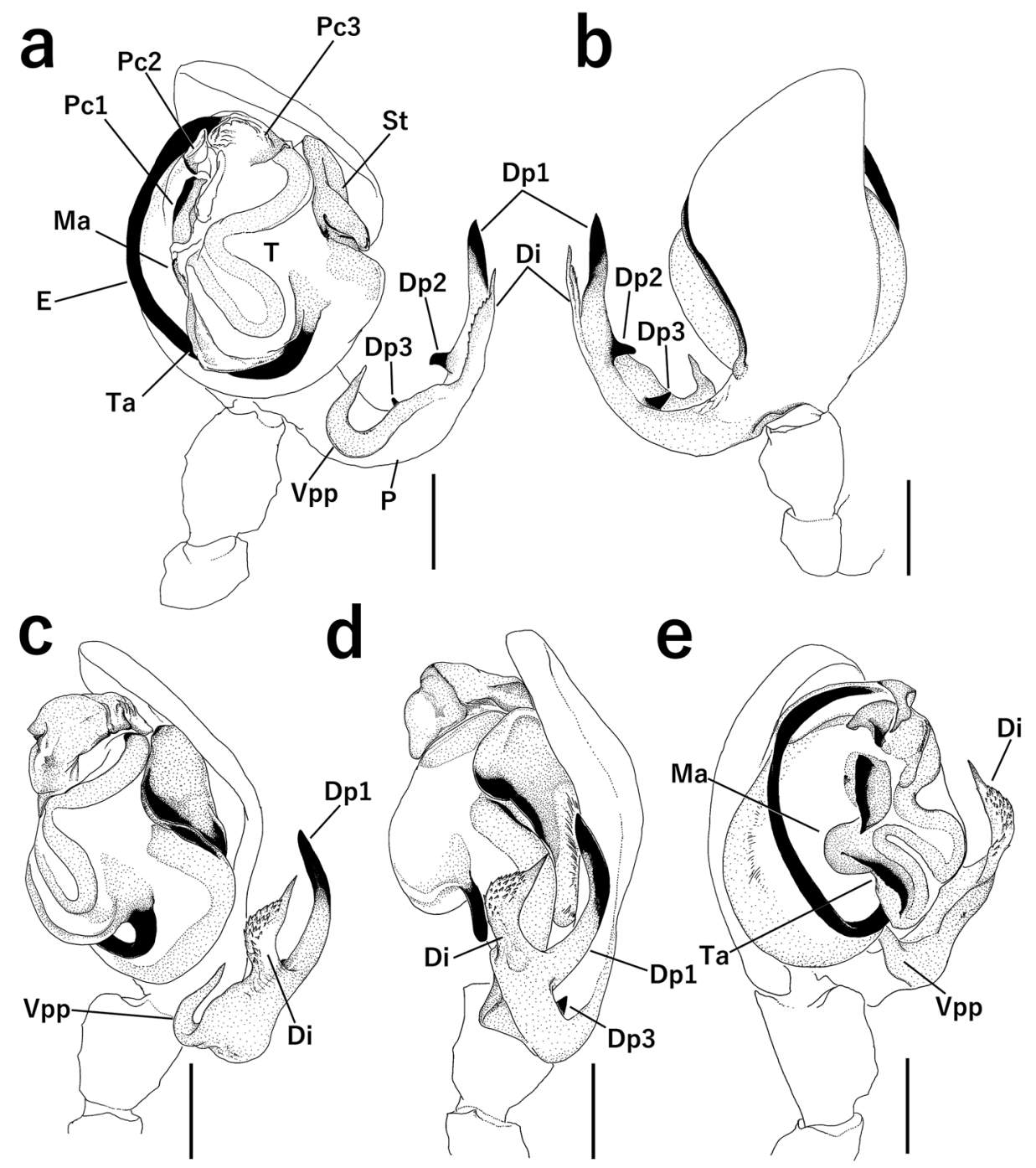

Figure 6. Male palp of $N$. latiscapus (illustrated). a Ventral view $\mathbf{b}$ dorsal view $\mathbf{c}$ ventro-retrolateral view d retrolateral view e ventro-prolateral view. Scale bars: $0.2 \mathrm{~mm}$.

4.60, 4.04, 1.65), II 11.78 (3.38, 0.81, 3.16, 3.04, 1.39), III 8.68 (2.77, 0.75, 1.90, 2.10, 1.16), IV $11.99(3.81,0.81,3.07,2.97,1.33)$.

Epigyne and vulva as in Figs 7, 8d. Scapus prolonged posteriorly, duck beakshaped, almost the same width or slightly wider towards the tip, ending with slightly divergent edges and lobate corners. Edge of copulatory openings straight, parallel towards the edges of the scapus. Insemination and fertilization ducts reaching spermathecae with a short and convoluted trait. Spermathecae oval. Vulval pockets wrinkled, located above spermathecae.

Distribution. Endemic to the Fuji Mountain area in central Honshu, Japan (Yamanashi Prefecture). See Fig. 10. 


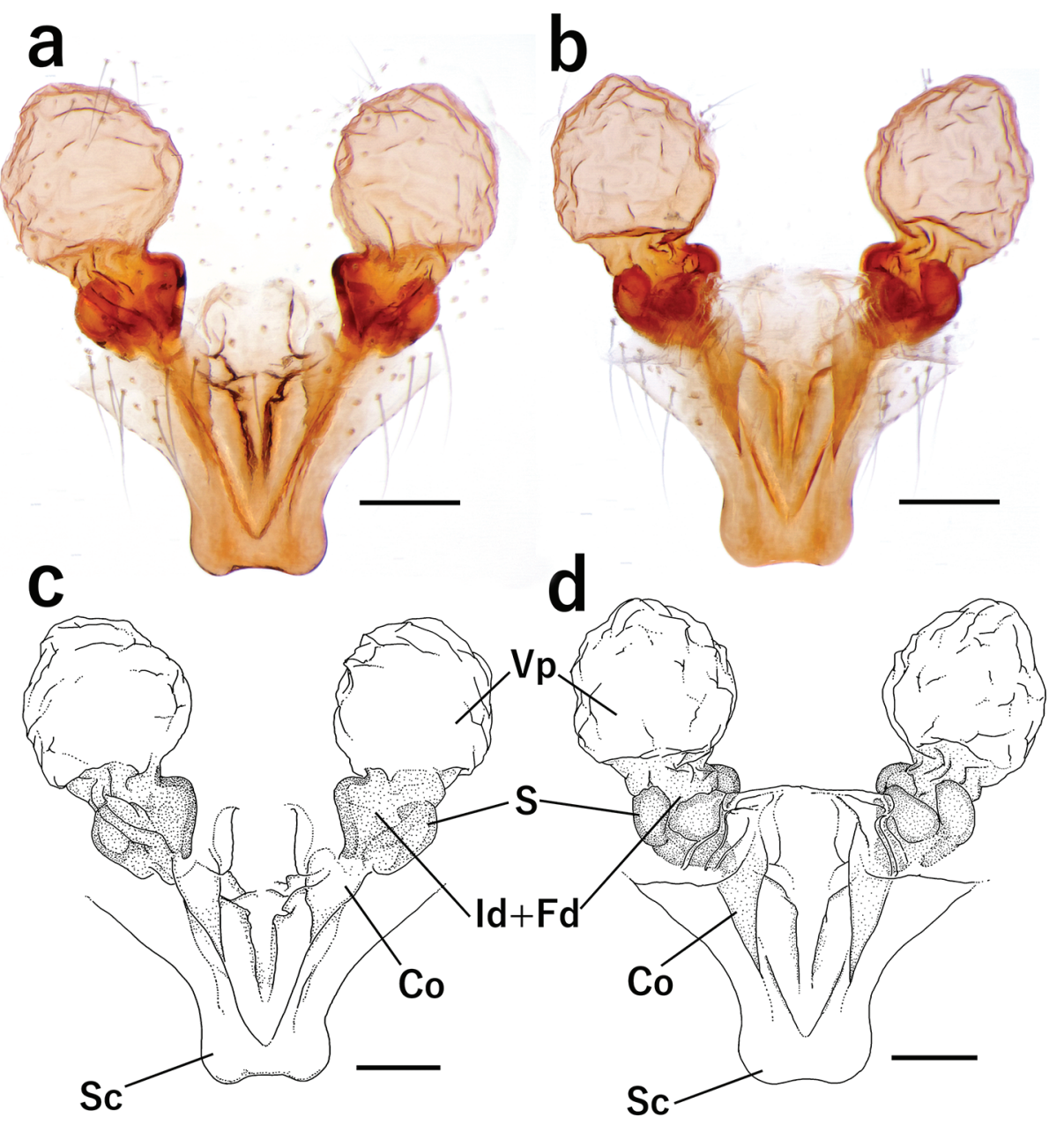

Figure 7. Female genitalia of $N$. latiscapus from Saiko Bat Cave. a, c Epigyne, ventral view b, d vulva, dorsal view. Scale bars: $0.2 \mathrm{~mm}$.

\section{Discussion}

\section{Remarks on autoecology of Nesticus kosodensis stat. nov. and N. latiscapus}

Although lacking deep morphological adaptations to a strict hypogean lifestyle, both $N$. kosodensis stat. nov. and $N$. latiscapus share a clear preference for troglophilic habitats, being mainly found in the twilight zone of caves or other similar environments. $N$. latiscapus inhabits the lava tubes located in the Aokigahara area and other surroundings northwest of Mount Fuji, thus apparently preferring this typology of basaltic superficial caves rather than the more common limestone caves. $N$. kosondensis stat. nov. seems to dwell in a wider range of subterranean or semi-subterranean habitats along the southern area of Okuchichibu Mountains Region, from large limestone caves to deep rocks cracks and large, empty spaces under stones and screes. Despite neighbor- 

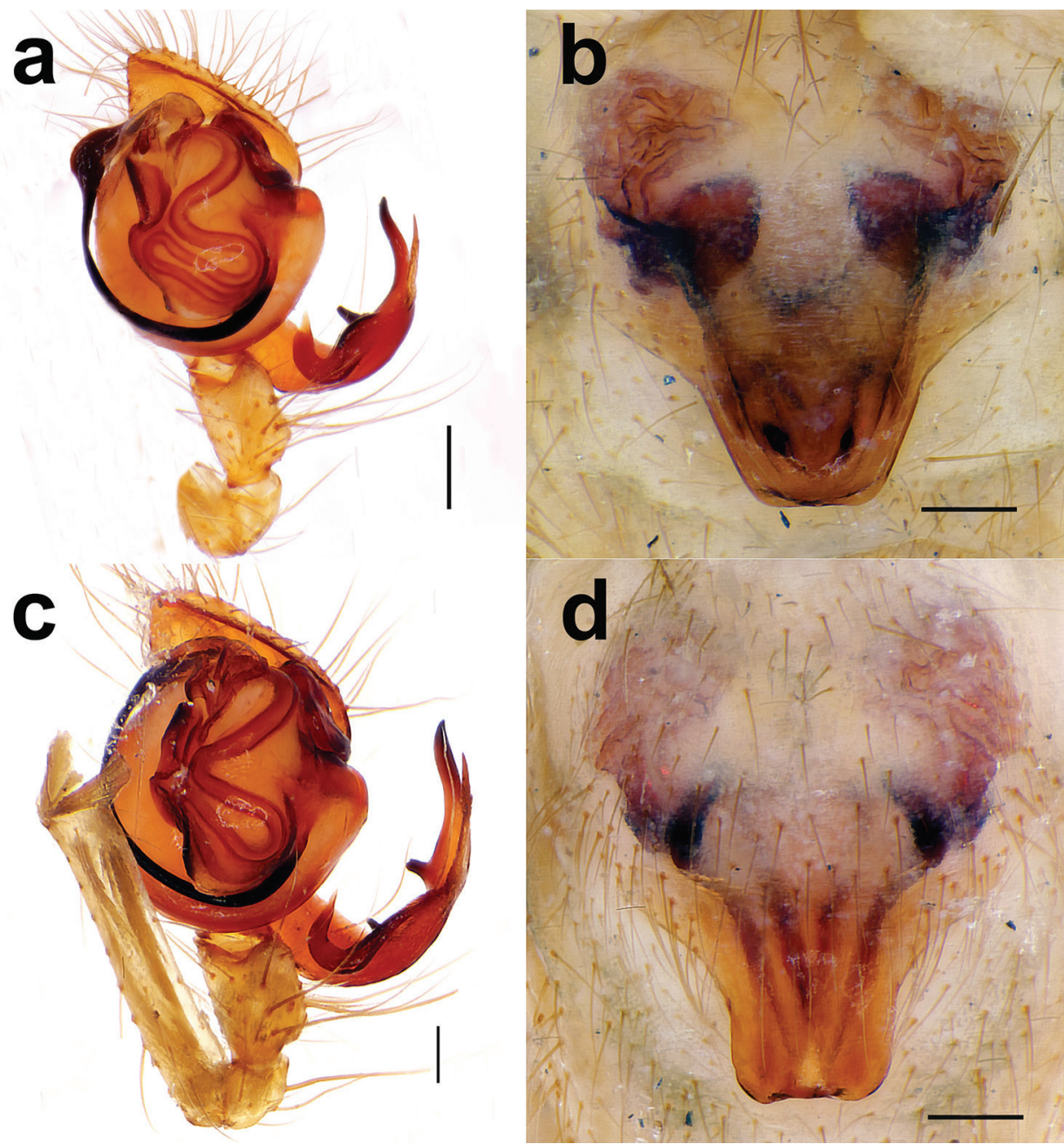

Figure 8. Type material of the species discussed in this work. Nesticus kosodensis stat. nov.: a palp of the holotype, ventral view $\mathbf{b}$ epigyne of the paratype, ventral view; $N$. latiscapus: $\mathbf{c}$ palp of the holotype, ventral view $\mathbf{d}$ epigyne of the paratype, ventral view. Scale bars: $0.2 \mathrm{~mm}$.

ing each other, these species seem to have an allopatric distribution, their ranges being approximately $30 \mathrm{~km}$ far from each other (Yaginuma 1972, 1979). Known records of $N$. kosodensis stat. nov. and N. latiscapus are reported in Fig. 10.

\section{Impact of species/subspecies delimitation on conservation of Japanese cave fauna}

All Japanese nesticids subspecies are currently know from sporadic records only, being limited to one cave (C. floronoides notoi, $C$. floronoides tatoro, $N$. longiscapus awa, $N$. longiscapus draco, $N$. tosa iwaya, $N$. tosa niyodo) or just few localities from a restrict- 


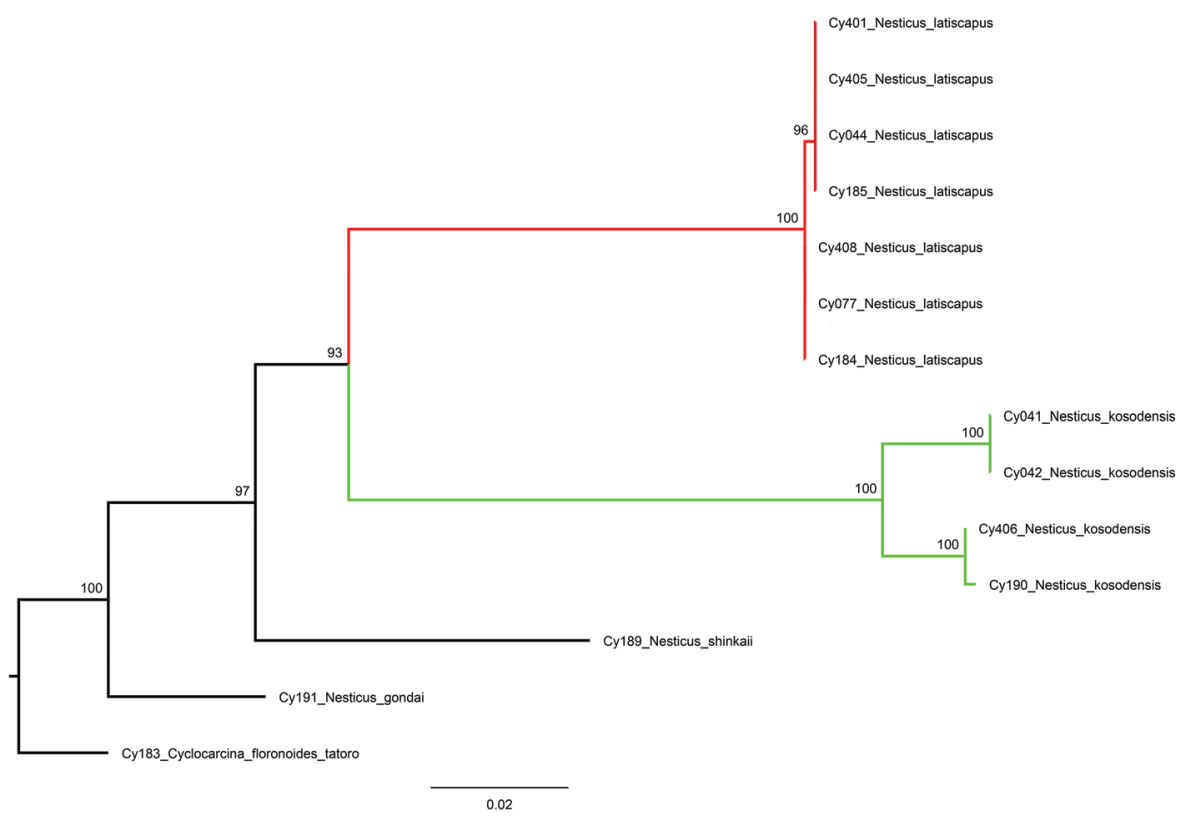

Figure 9. Phylogenetic relationship among Nesticus latiscapus (= red), N. kosodensis stat. nov. (= green), and other closely-related species from the same geographic area (=black) inferred from ML analysis of COI partial sequence. Branch lengths are scaled in relation to the number of substitutions per site. Numbers at nodes denote maximum likelihood bootstrap support.

ed area (C. floronoides komatsui, Nesticus akiyoshiensis ofuku) (Yaginuma 1976, 1978, 1979). They apparently share small differences in the morphology of genitalia and a parapatric or allopatric distribution with widely distributed conspecifics from the same area. Furthermore, their attribution to an intraspecific rank rather than a separate, well-defined species was mainly based on traits which are not clearly distinguishable (Yaginuma 1979). Thus, it is unclear if such spiders should be considered as real endemic or just local variations of widely distributed species.

Endemic subterranean organisms, including cave spiders, are considered a priority target for species conservation since they are prone to extinction due to local or global environmental changes (Mammola et al. 2018). Nevertheless, our ability to correctly separate species and subspecies may have an impact on the establishment of protective actions for cave fauna.

Incorrectly defining a valid species as a subspecies may underestimate the biodiversity of a cave, and thus fail to identify biodiversity hotspots and potentially endangered species. In turn, efforts spent for their protection may be insufficient, potentially causing the loss of endemic organisms even before they are discovered. On the other hand, correctly evaluating the existence of geographic variants of widely-distributed species may enable more efficient and effective prioritization in conservation projects. Widelydistributed organisms are often less vulnerable than endemic taxa, and have lower con- 


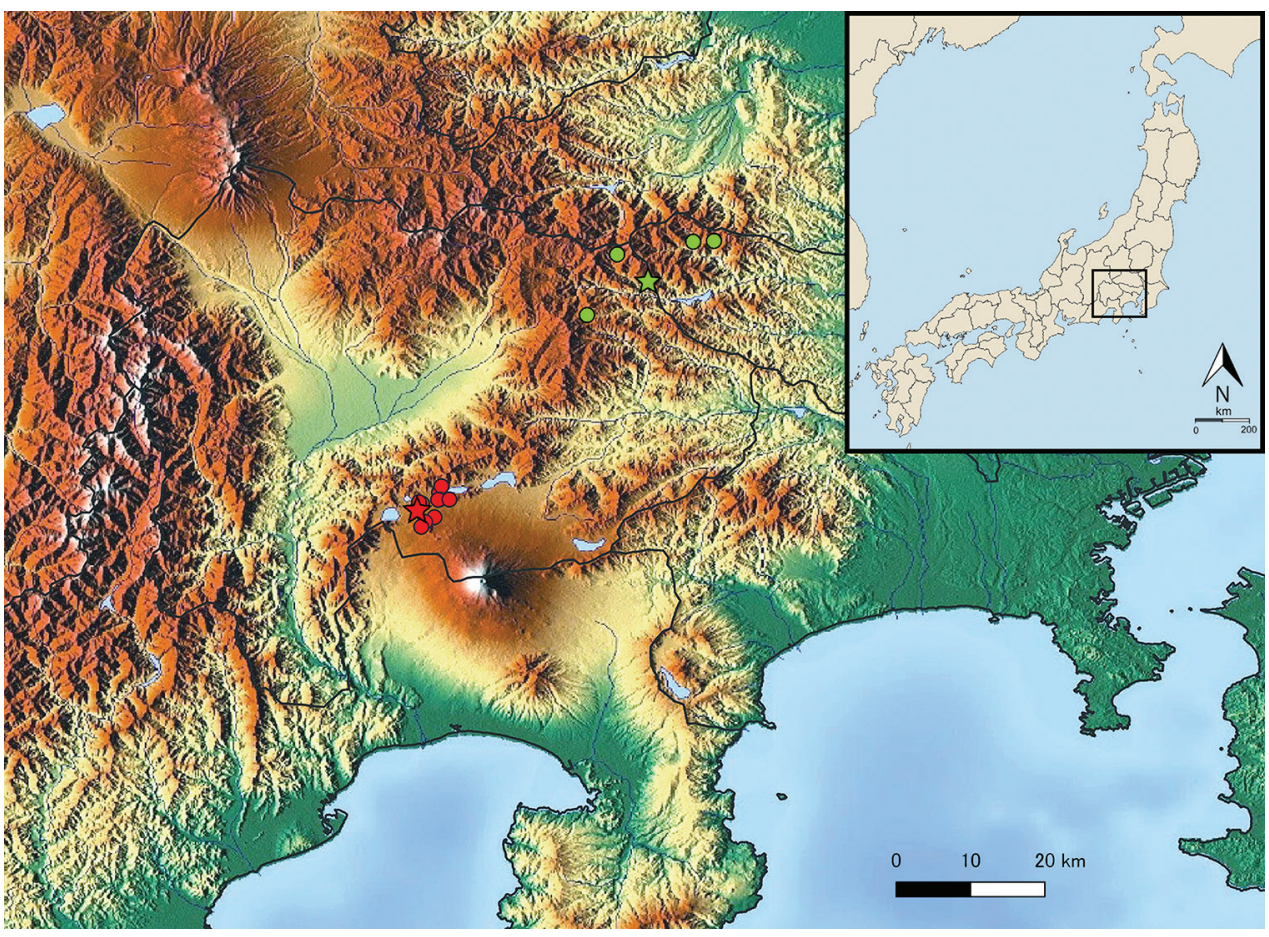

Figure 10. Distribution of Nesticus kosodensis stat. nov. (green dots) and N. latiscapus (red dots) in Japan. Stars show the type localities of the species.

servation priority (Primack 2006). Using limited economic resources to protect least concern species may distribute funding away from more threatened species.

Revising the taxonomic position of long-established and uncertain subspecies, like in the case of the Japanese nesticid spiders, can therefore be worthwhile in terms of conservation, especially in countries hosting several unique endemic species like Japan.

\section{Conclusions}

Both morphological and molecular analysis suggest that $N$. latiscapus is distinct from $N$. kosodensis stat. nov., rejecting the status of subspecies for $N$. kosodensis stat. nov. In the light of these results, the elevation of $N$. kosodensis stat. nov. to the rank of species is herein proposed. Our results further highlight that future work should investigate the remaining Japanese nesticid subspecies, as well as other spider subspecies, including from a conservation perspective.

It is likely that new, detailed studies involving both morphological and molecular comparison may lead to the rise of more of these interspecific ranks to valid species, thus further increasing the already high diversity of the family Nesticidae in Japan, and Japanese cave fauna in general. Such result may also help to promote new and more correct conservation plans to preserve the endemic cave spider fauna in Japan. 


\section{Acknowledgements}

The authors are particularly grateful to Katsuyuki Eguchi for providing the use of microscope and other facilities at the Systematic Zoology Laboratory, Tokyo Metropoli$\tan$ University, and to Ryosuke Kuwahara for the photograph of male N. kosodensis stat. nov. Many thanks to Marta Quitián, Isaac Planas-Sitjà, Tatsumi Suguro and Takeshi Yamasaki for helping with the field collections and providing additional material used in this study. We also thank Ken-ichi Okumura for allowing us to study the type material preserved in the National Museum of Nature and Science, Tokyo, Japan. Many thanks to Victoria Smith (Canterbury Museum, New Zealand) for checking the English text of an early draft of the manuscript. We are thankful to Akio Tanikawa, Takeshi Yamasaki and an anonymous reviewer for their suggestions which helped to improve the manuscript. This work was supported by the YF2018 Japan Society for the Promotion of Science (JSPS KAKENHI n ${ }^{\circ} 18 \mathrm{~F} 18380$ ) Postdoctoral Fellowships, Japan.

\section{References}

Darriba D, Taboada GL, Doallo R, Posada D (2012) jModelTest 2: more models, new heuristics and parallel computing. Nature methods 9(8): 772-772. https://doi.org/10.1038/nmeth.2109

Folmer O, Black M, Hoeh W, Lutz R, Vrijenhoek R (1994) DNA primers for amplification of mitochondrial cytochrome c oxidase subunit I from diverse metazoan invertebrates. Molecular Marine Biology and Biotechnology 3: 294-299.

Hedin MC, Maddison WP (2001) A combined molecular approach to phylogeny of the jumping spider subfamily Dendryphantinae (Araneae: Salticidae). Molecular Phylogenetics and Evolution 18: 386-403. https://doi.org/10.1006/mpev.2000.0883

ICZN (2012) International Code of Zoological Nomenclature. Fourth Edition. Incorporating Declaration 44, amendments of Article 74.7.3, with effect from 31 December 1999 and the Amendment on e-publication, amendments to Articles 8, 9, 10, 21 and 78, with effect from 1 January 2012. http://www.iczn.org/iczn/ https://doi.org/10.3897/zookeys.219.3994

Katoh K, Rozewicki J, Yamada KD (2019) MAFFT online service: multiple sequence alignment, interactive sequence choice and visualization. Briefings in Bioinformatics 20: 1160-1166. https://mafft.cbrc.jp/alignment/software/ https://doi.org/10.1093/bib/bbx108

Kraus O (2000) Why no subspecies in spiders? In: Toft, Scharff (Eds) European Arachnology: 303-314.

Kumar S, Stecher G, Li M, Knyaz C, Tamura K (2018) MEGA X: molecular evolutionary genetics analysis across computing platforms. Molecular Biology and Evolution 35(6): 1547-1549. https://doi.org/10.1093/molbev/msy096

Mammola S, Goodacre SL, Isaia M (2018) Climate change may drive cave spiders to extinction. Ecography 41(1): 233-243. https://doi.org/10.1111/ecog.02902

Miller MA, Pfeiffer W, Schwartz T (2010) Creating the CIPRES Science Gateway for inference of large phylogenetic trees. Proceedings of the Gateway Computing Environments Workshop (GCE), 14 Nov. 2010, New Orleans, 1-8. https://doi.org/10.1109/ GCE.2010.5676129 
Nentwig, W, Blick T, Gloor D, Jäger P, Kropf C (2019) Tackling taxonomic redundancy in spiders: the infraspecific spider taxa described by Embrik Strand (Arachnida: Araneae). Arachnologische Mitteilungen: Arachnology Letters 58(1): 29-51. https://oi.org/10.30963/ aramit5809

Primack RB (2014) Essentials of Conservation Biology. Sixth edition. Sinauer Assoc., Inc., Publisher Sunderland, Massachusetts, 603 pp.

Stamatakis A (2014) RAxML version 8: a tool for phylogenetic analysis and post-analysis of large phylogenies. Bioinformatics 30(9): 1312-1313. https://doi.org/10.1093/bioinformatics/btu033

TanikawaA(2020)ACheckListofJapaneseSpidersver.2020R1.http:/www.asahi-net.or.jp/ dp7atnkw/japan.pdf [accessed March, 2020] https://doi.org/10.22233/20412495.0320.1

Wiens JJ (2007) Species delimitation: New approaches for discovering diversity. Systematic Biology 56: 875-878. https://doi.org/10.1080/10635150701748506

World Spider Catalog (2020) World Spider Catalog. Version 21.0: Natural History Museum Bern. http://wsc.nmbe.ch [accessed March, 2020]

Yaginuma T (1972) The fauna of the lava caves around Mt. Fuji-san IX. Araneae (Arachnida). Bulletin of the National Museum of Nature and Science Tokyo 15: 267-334.

Yaginuma T (1976) Nesticid spiders (Araneae, Nesticidae) of Kôchi Prefecture, Shikoku, Japan. Journal of the Speleological Society of Japan 1: 16-27.

Yaginuma T (1977) Some problems in cave spiders of Japan (including a description of a new species). Faculty of Letters Revue, Otemon Gakuin University 11: 305-316.

Yaginuma T (1978) Nesticid spiders of Shikoku, Japan. Faculty of Letters Revue, Otemon Gakuin University 12: 151-160.

Yaginuma T (1979) A study of the Japanese species of nesticid spiders. Faculty of Letters Revue, Otemon Gakuin University 13: 255-287. 